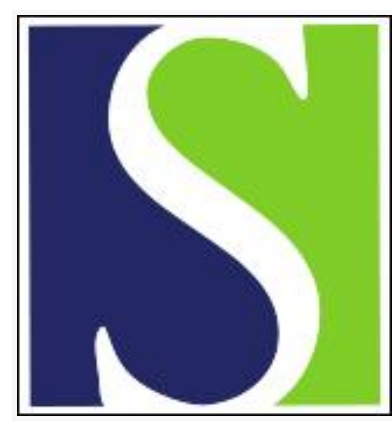

Scand J Work Environ Health 1993;19(2):85-88

https://doi.org/10.5271/sjweh.1493

Issue date: 01 Apr 1993

\title{
Mortality of army cooks.
}

by Coggon D, Wield $\mathrm{G}$

Affiliation: MRC Environmental Epidemiology Unit, University of Southampton, Southampton General Hospital, United Kingdom.

The following article refers to this text: SJWEH Supplements 2009;(7):24-29

This article in PubMed: www.ncbi.nlm.nih.gov/pubmed/8316783

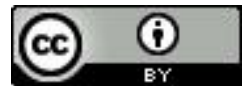




\title{
Mortality of army cooks
}

\author{
by David Coggon, FRCP, Graham Wield, $\mathrm{BSc}^{1}$
}

\begin{abstract}
COGGON D, WIELD G. Mortality of army cooks. Scand J Work Environ Health 1993;19:85-8. The possible hazard of lung cancer among cooks was studied in a cohort of 1798 cooks who had retired from the Army Catering Corps and 1310 referents retired from the Royal Army Pay Corps. During the follow-up from 1974 to 1989 the mortality of the referents was similar to that of the national population, apart from a moderate increase in lung cancer [standardized mortality ratio (SMR) 1.38]. Mortality from lung cancer among the cooks was significantly higher than among the national population [SMR 1.82, 95\% confidence interval (95\% CI) $1.25-2.57$ ], as was mortality from cancer of the large intestine (SMR 3.03), ischemic heart disease (SMR 1.42), cerebrovascular disease (SMR 2.05), and digestive disease (SMR 2.27). The high rate of lung cancer among the cooks supports the hypothesis of an occupational hazard, although at least part of the excess was probably due to smoking. Possible explanations for the elevated mortality from other diseases include poor nutrition in early life, smoking, and high consumption of alcohol.
\end{abstract}

Key terms: cerebrovascular disease, colon cancer, ischemic heart disease, lung cancer.

Routine analyses of occupational mortality in Great Britain (1-3) and Denmark (4), and of cancer incidence by occupation in California (5), have indicated high rates of lung cancer in cooks. These observations are supported by the results of two case-referent studies $(6,7)$. To explore further the risk of lung cancer associated with work as a cook, we have carried out a cohort study of retired members of the Army Catering Corps.

\section{Subjects and methods}

The study cohort comprised all retired cooks from the Army Catering Corps who were on the reserve list (ie, members of the regular army reserve, the Territorial Army, or the Ulster Defence Regiment) at any time between 1 January 1974 and 31 December 1984. As an internal control we took retired members of the Royal Army Pay Corps who were on the reserve list during the same 11-year period. All of the subjects were men. Most of the soldiers studied would have joined the Army soon after leaving school, entry to a particular Corps being determined by personal choice and aptitude. They would then have received training in their chosen trade. The work of the Pay Corps is largely clerical. While in regular service, members of both the Catering and

\footnotetext{
1 MRC Environmental Epidemiology Unit, University of Southampton, Southampton General Hospital, Southampton.
}

Reprint requests to: Dr D Coggon, MRC Environmental Epidemiology Unit, University of Southampton, Southampton General Hospital, Southampton, S09 4XY, United Kingdom. the Pay Corps undertake physical training, and both groups are required to work irregular hours.

The study and reference cohorts were identified from computerized pension records which included surname, initials, date of birth, last known address, National Insurance number, and dates of last entering and leaving regular service. Full first names were obtained from social security records by linkage through the National Insurance number, surname, and date of birth, and with this additional information subjects were traced through the National Health Service Central Register up to 31 December 1989. For those men who had died, death certificates were obtained with the underlying cause of death coded to the ninth revision of the International Classification of Diseases.

In the analysis, the subjects were considered to be at risk from 1 January 1974 or their date of entry to the reserve list, whichever was later. The mortality of the study and reference cohorts was compared with that of the national population by the personyears method, the expected numbers of deaths being calculated for five-year age and calendar intervals, and the $95 \%$ confidence intervals $(95 \% \mathrm{CI})$ for standardized mortality ratios (SMR) being based on the Poisson distribution. In addition, the death rates of the two cohorts were compared directly by Poisson regression analysis (8).

From the pension records we identified 1798 retired cooks and 1310 referents. At least $74.6 \%$ of the cooks and $78.2 \%$ of the referents had completed more than 20 years of regular service. (The exact proportions were unknown because, for men who had left the army and then reenlisted, information was only available for the most recent period of service.)

Table 1 summarizes the outcome of the tracing exercise. Altogether, $92.4 \%$ of the cooks and $93.6 \%$ 
Table 1. Outcome of the tracing.

\begin{tabular}{lrc}
\hline & Cooks & Referents \\
\cline { 2 - 3 } Untraced in social security records & - & 1 \\
Untraced at the National Health & 136 & 83 \\
Service Central Register & 22 & 11 \\
Emigrated before 1 January 1974 & 20 & 12 \\
Emigrated during follow-up period & 227 & 150 \\
Died during follow-up period & 1393 & 1053 \\
Alive at end of follow-up & 1798 & 1310 \\
\hline Total & \multicolumn{2}{|c}{} \\
\hline
\end{tabular}

of the referents were successfully traced through the National Health Service Central Register. The untraced subjects were excluded from further analysis, together with 33 men who had emigrated before the start of the follow-up period. Another 32 subjects who emigrated during follow-up were considered at risk up to the date of their migration.

\section{Results}

By the end of 1989, 227 deaths had occurred among the cooks and 150 among the referents. Table 2 shows the mortality of the cooks and referents as compared with that of the national population. The overall death rate of the reference group was close to expectation (SMR 1.06, 95\% CI 0.89-1.24), as was mortality from most of the common causes of death. The exception was lung cancer, for which mortality was moderately elevated, although not to the point of statistical significance (SMR 1.38, 95\% CI $0.88-2.07$ ). In contrast, the cooks had significantly elevated death rates from all causes (SMR
1.48, 95\% CI 1.30-1.69), all cancers (SMR 1.41, 95\% CI 1.09-1.80), cancer of the large intestine (SMR 3.03, 95\% CI 1.39-5.75), lung cancer (SMR $1.82,95 \%$ Cl $1.25-2.57$ ), ischemic heart disease (SMR 1.42, 95\% CI 1.13-1.76), cerebrovascular disease (SMR 2.05, 95\% CI 1.22-3.24), and digestive disease (SMR 2.27, 95\% CI 1.04 4.30). When the analysis was restricted to those men who were known to have completed at least 20 years of service, the risk estimates were much the same.

Table 3 shows the mortality of the cooks relative to that of the referents for selected causes of death. In comparison with the death rates of the referents, those of the cooks were significantly elevated for all causes combined [risk ratio (RR) $1.41,95 \% \mathrm{CI}$ 1.14-1.73) and, specifically, for cancer of the large intestine (all nine cases occurred among the cooks) and circulatory disease (RR $1.45,95 \%$ CI $1.07-$ 1.96). The last-mentioned category reflected excesses of both ischemic heart disease (RR 1.43) and cerebrovascular disease (RR 2.17). Mortality from lung cancer was higher among the cooks, but the difference was not statistically significant (RR $1.29,95 \%$ CI 0.76-2.21). A similar increase in risk was observed for other smoking-related cancers (RR 1.24), but not for respiratory disease (RR 1.04). The nine deaths from digestive disease among the cooks (RR 2.93 ) included four from peptic ulcer, four from cirrhosis or alcoholic liver disease, and one from intestinal obstruction.

\section{Discussion}

The proportion of untraced subjects was higher in this investigation than in most industrial cohort stud-

Table 2. Mortality of the cooks and referents as compared with that of the national population. (SMR = standardized mortality ratio, $95 \% \mathrm{Cl}=95 \%$ confidence interval)

\begin{tabular}{|c|c|c|c|c|c|c|}
\hline \multirow[b]{2}{*}{ Cause of death ${ }^{\mathrm{a}}$} & \multicolumn{3}{|c|}{ Cooks } & \multicolumn{3}{|c|}{ Referents } \\
\hline & $\begin{array}{l}\text { Observed } \\
\text { deaths } \\
(N)\end{array}$ & SMR & $95 \% \mathrm{Cl}$ & $\begin{array}{l}\text { Observed } \\
\text { deaths } \\
\text { (N) }\end{array}$ & SMR & $95 \% \mathrm{Cl}$ \\
\hline All causes $(0-999)$ & 227 & 1.48 & $1.30-1.69$ & 150 & 1.06 & $0.89-1.24$ \\
\hline All cancers $(140-208)$ & 65 & 1.41 & $1.09-1.80$ & 50 & 1.16 & $0.86-1.53$ \\
\hline $\begin{array}{l}\text { Esophagus (150) } \\
\text { Stomach }(151) \\
\text { Large intestine (153) } \\
\text { Rectum }(154) \\
\text { Larynx }(161) \\
\text { Lung }(162-164) \\
\text { Melanoma (172) } \\
\text { Prostate (185) } \\
\text { Bladder (188) } \\
\text { Kidney (189) }\end{array}$ & $\begin{array}{r}4 \\
5 \\
9 \\
2 \\
2 \\
32 \\
1 \\
3 \\
2\end{array}$ & $\begin{array}{l}2.10 \\
1.37 \\
3.03 \\
0.95 \\
3.96 \\
1.82 \\
0.00 \\
0.70 \\
2.21 \\
1.68\end{array}$ & $\begin{array}{l}0.57-5.39 \\
0.44-3.20 \\
1.39-5.75 \\
0.12-3.42 \\
0.48-14.31 \\
1.25-2.57 \\
0.00-7.41 \\
0.02-3.91 \\
0.46-6.46 \\
0.20-6.07\end{array}$ & $\begin{array}{r}4 \\
2 \\
3 \\
1 \\
1 \\
23 \\
2 \\
2 \\
1 \\
3\end{array}$ & $\begin{array}{l}2.26 \\
0.58 \\
0.00 \\
1.53 \\
2.13 \\
1.38 \\
4.68 \\
1.42 \\
0.77 \\
2.76\end{array}$ & $\begin{array}{l}0.62-5.79 \\
0.07-2.11 \\
0.00-1.34 \\
0.31-4.47 \\
0.05-11.86 \\
0.88-2.07 \\
0.57-16.92 \\
0.17-5.14 \\
0.02-4.31 \\
0.57-8.06\end{array}$ \\
\hline Circulatory disease $(390-459)$ & 110 & 1.45 & $1.19-1.75$ & 70 & 0.99 & $0.77-1.25$ \\
\hline $\begin{array}{l}\text { Ischemic heart disease }(410-414) \\
\text { Cerebrovascular disease }(430-438)\end{array}$ & $\begin{array}{l}83 \\
18\end{array}$ & $\begin{array}{l}1.42 \\
2.05\end{array}$ & $\begin{array}{l}1.13-1.76 \\
1.22-3.24\end{array}$ & $\begin{array}{r}53 \\
8\end{array}$ & $\begin{array}{l}0.98 \\
0.97\end{array}$ & $\begin{array}{l}0.73-1.27 \\
0.42-1.91\end{array}$ \\
\hline Respiratory disease $(460-519)$ & 12 & 1.22 & $0.63-2.13$ & 11 & 1.17 & $0.58-2.09$ \\
\hline Digestive disease $(008-009,520-579)$ & 9 & 2.27 & $1.04-4.30$ & 3 & 0.84 & $0.17-2.46$ \\
\hline Injuries and poisoning $(800-999)$ & 6 & 0.71 & $0.26-1.54$ & 7 & 0.97 & $0.39-2.00$ \\
\hline
\end{tabular}

a Code of the International Classification of Diseases, ninth revision, in parentheses. 
ies, probably because some of the men went to live abroad soon after leaving the regular army and never registered with a physician in the National Health Service. If so, the incomplete tracing would not be expected to produce any serious bias, especially in internal comparisons with the referents from the Pay Corps.

Overall mortality in the reference group was similar to that in the national population. Given that entry to the study was through registration on the reserve list, it is perhaps surprising that a healthy worker effect was not apparent. Chronically disabled soldiers are excluded from entry to the reserve, but this selection does not seem to have any strong longterm impact on mortality.

The only common cause of death with markedly increased incidence in the reference group was lung cancer (SMR 1.38). It seems likely that this excess is attributable, at least in part, to high rates of smoking. No data are available on the prevalence of smoking in the Pay Corps specifically, but, in the Army as a whole, the habit has been common. In a survey of 15- to 18-year-old entrants to the Army in 1959, $76 \%$ had smoked during the previous four weeks and $53 \%$ smoked at least 20 cigarettes per week (9). Smoking habits may also have accounted for the referents' increased mortality from respiratory disease. Members of the Pay Corps are not exposed to any known occupational causes of lung cancer.

Mortality from lung cancer among the cooks was even higher than among the referents, and it was significantly elevated in comparison with national rates (SMR 1.82). Again, smoking may have contributed to this excess, although it would be unusual to observe such a high mortality ratio solely through the confounding effect of smoking (10). Certainly, the finding would be compatible with an occupational hazard, as suggested by earlier studies (1-7). Most of the cooking in the Army is carried out in permanent rather than field kitchens, mainly using gas rather than electricity, and includes a lot of frying. A hazard of lung cancer might arise from the fumes generated during cooking, particularly when food is fried. Such fumes are known to be mutagenic (11, 12), and in two Chinese case-referent studies frequent frying and smokiness during cooking were associated with an increased risk of lung cancer $(13,14)$.

The high mortality from other causes among the cooks, particularly from circulatory and digestive disease, is also compatible with the findings of other studies $(1-3)$. Four of the nine observed deaths from digestive disease were ascribed to cirrhosis or alcoholic liver disease, and it seems likely that cooks drink more heavily than the average - perhaps because alcohol is more readily available to them.

The death rates from circulatory disease were significantly elevated not only in comparison with the national population, but also relative to the internal reference group. Cooking fumes do not contain any known cardiotoxins which would explain this excess.
Table 3. Mortality of the cooks relative to that of the referents, as estimated by a Poisson regression analysis. (95\% $\mathrm{Cl}=95 \%$ confidence interval)

\begin{tabular}{lcc}
\hline Cause of death & Risk ratio & $95 \% \mathrm{CI}$ \\
\hline All causes & 1.41 & $1.14-1.73$ \\
All cancers & 1.20 & $0.83-1.74$ \\
$\quad$ Cancer of the large intestine & All 9 cases were cooks \\
Cancer of the lung & 1.29 & $0.76-2.21$ \\
Other smoking-related $_{\text {cancers }^{\mathrm{a}}}$ & 1.24 & $0.52-2.96$ \\
Circulatory disease $_{\text {Ischemic heart disease }}$ & 1.45 & $1.07-1.96$ \\
$\quad$ Cerebrovascular disease & 1.43 & $1.01-2.02$ \\
Respiratory disease & 2.17 & $0.94-4.99$ \\
Digestive disease & 1.04 & $0.46-2.35$ \\
\end{tabular}

a Cancers of the lip, tongue, mouth, esophagus, pancreas, larynx, bladder, and kidney.

Smoking may contribute, but it would be unlikely to account fully for such a large increase in cardiovascular mortality. Another possibility is that recruits to the Catering Corps come from a different social background from those entering the Pay Corps. Evidence is mounting that nutrition in early life has an important influence on later risk of circulatory disease, acting through a variety of pathogenetic mechanisms (15-18). A cross-sectional survey of cardiovascular risk factors among current members of the Catering Corps might help to clarify the reasons for the high mortality from vascular disease in our study.

In contrast to the findings on other causes of death, the high mortality of the cooks from colonic cancer was unexpected. No similar increase in risk has been found in routine analyses of occupational mortality $(2,3)$, and no aspect of cooking is suspected of strongly influencing the risk of large bowel cancer. The observation may, therefore, be a chance phenomenon. If so, the excess should diminish with continued follow-up.

In summary, this study supports the hypothesis that work as a cook increases the risk of lung cancer, although a spurious association from a confounding effect of smoking cannot be totally ruled out. It also indicates that retired members of the Catering Corps have unusually high mortality from circulatory disease. A survey of risk factors for vascular disease among current members of the Catering Corps might help to explain this observation and allow appropriate preventive measures to be instituted.

\section{Acknowledgments}

We thank the Army, and particularly the Royal Army Medical Corps, for their help in setting up the study; the staff of the National Health Service Central Register and Department of Social Security for their assistance in the tracing exercise; and Dr C Osmond for his help with the statistical analysis. 


\section{References}

1. Registrar General. Decennial supplement England and Wales 1961: occupational mortality. London: Her Majesty's Stationery Office, 1971.

2. Office of Population Censuses and Surveys. Occupational mortality decennial supplement 1970-1972 England and Wales. London: Her Majesty's Stationery Office, 1978.

3. Office of Population Censuses and Surveys. Occupational mortality decennial supplement 1979-80 1982-83 Great Britain. London: Her Majesty's Stationery Office, 1986.

4. Danmarks Statistik. Dødelighed 1970-80 [Mortality 1970 - 80]. Copenhagen: Danmarks statistik, 1985.

5. Menck HR, Henderson BE. Occupational differences in rates of lung cancer. J Occup Med 1976;18:797801.

6. Coggon D, Pannett B, Acheson ED. Use of job-exposure matrix in occupational analysis of lung and bladder cancers on the basis of death certificates. J Natl Cancer Inst 1984;72:61-5.

7. Coggon D, Pannett B, Osmond C, Acheson ED. A survey of cancer and occupation in young and middle aged men: $\mathrm{I}$. cancers of the respiratory tract. $\mathrm{Br} \mathrm{J}$ Ind Med 1986;43:332-8.

8. Breslow NE, Day NE. Statistical methods in cancer research; vol II (The design and analysis of cohort studies). Lyon: International Agency for Research on Cancer, 1987.

9. Crowdy JP, Lewthwaite CJ, Sowden RR. Smoking: the changing habits of male adolescents: a comparison of three generations of young soldiers. JR Army Med
Corps 1975;121:126-31.

10. Axelson $O$. Aspects on confounding in occupational health epidemiology. Scand $\mathbf{J}$ Work Environ Health 1978;4:98-102.

11. Rappaport SM, McCartney MC, Wei ET. Volatilization of mutagens from beef during cooking. Cancer Lett 1979;8:139-45.

12. Qu YH, Xu GX, Huang F, Fang JC, Gao YT. An Ames test on other by-products of the heating of cooking oils. Tumor 1986;6:58-60.

13. Gao YT, Blot WJ, Zheng W, Ershow AG, Hsu CW, Levin LI, et al. Lung cancer among Chinese women. Int J Cancer 1987;40:604-9.

14. Wu-Williams AH, Dai XD, Blot W, Xu ZY, Sun XW, Xiao HP, et al. Lung cancer among women in northeast China. Br J Cancer 1990;62:982-7.

15. Barker DJP, Winter PD, Osmond C, Margetts B, Simmonds SJ. Weight in infancy and death from ischemic heart disease. Lancet 1989;2:557-80.

16. Barker DJP, Bull AR, Osmond C, Simmonds SJ. Foetal and placental size and risk of hypertension in adult life. Br Med J 1990;301:259-62.

17. Hales CN, Barker DJP, Clark PMS, Cox LJ, Fall C, Osmond C, Winter PD. Foetal and infant growth and impaired glucose tolerance at age 64. Br Med J 1991; 303:1019-22.

18. Fall CHD, Barker DJP, Osmond C, Winter PD, Clark PMS, Hales CN. Relation of infant feeding to adult serum cholesterol concentration and death from ischaemic heart disease. Br Med J 1992;304:801-5.

Received for publication: 31 July 1992 